\title{
3D printing for development of medical equipment amidst coronavirus (COVID-19) pandemic_-review and advancements
}

\author{
Mir Irfan UI Haq ${ }^{1}$ - Suhail Khuroo ${ }^{2}$ - Ankush Raina ${ }^{1}$ - Sabiyata Khajuria ${ }^{3} \cdot$ Mohd Javaid $^{4} \cdot$ Mir Farhan UI Haq $^{5}$. \\ Abid Haleem ${ }^{4}$
}

Received: 8 June 2020 / Accepted: 22 September 2020 / Published online: 1 October 2020

(C) Sociedade Brasileira de Engenharia Biomedica 2020

\begin{abstract}
Background and aims Coronavirus (COVID-19) has surfaced as a global pandemic and has created an unprecedented global demand for medical equipment. The shortage of onsite workforce, need for social distancing and less time available for sourcing have further made it difficult for the governments and the medical professionals to combat the pandemic. This study's prime objective is to review the advancements in the area of 3D printing to develop medical equipment and explore the potential of 3D printing in addressing the shortage of medical equipment mainly the personal protective equipment (PPE) amidst COVID-19 pandemic.

Methods 3D printing or additive manufacturing has emerged as a new manufacturing process with tremendous potential to develop complex products in short time with minimal human interventions. The paper summarises 3D printing's potential to serve the increasing need for medical equipment, mainly personal protective equipment (PPE) and ventilator equipment in the ongoing global COVID-19 pandemic.

Results The minimum human interventions required to carry out production using $3 \mathrm{D}$ printing also make the technology an excellent option to deal with the current situation.

Conclusions The recommendations and opinions presented in the paper shall act as a stimulant to develop components very critical for the pandemic and help save precious lives globally.
\end{abstract}

Keywords 3D printing $\cdot$ COVID-19 $\cdot$ Coronavirus $\cdot$ Design $\cdot$ Pandemic $\cdot$ Medical equipment

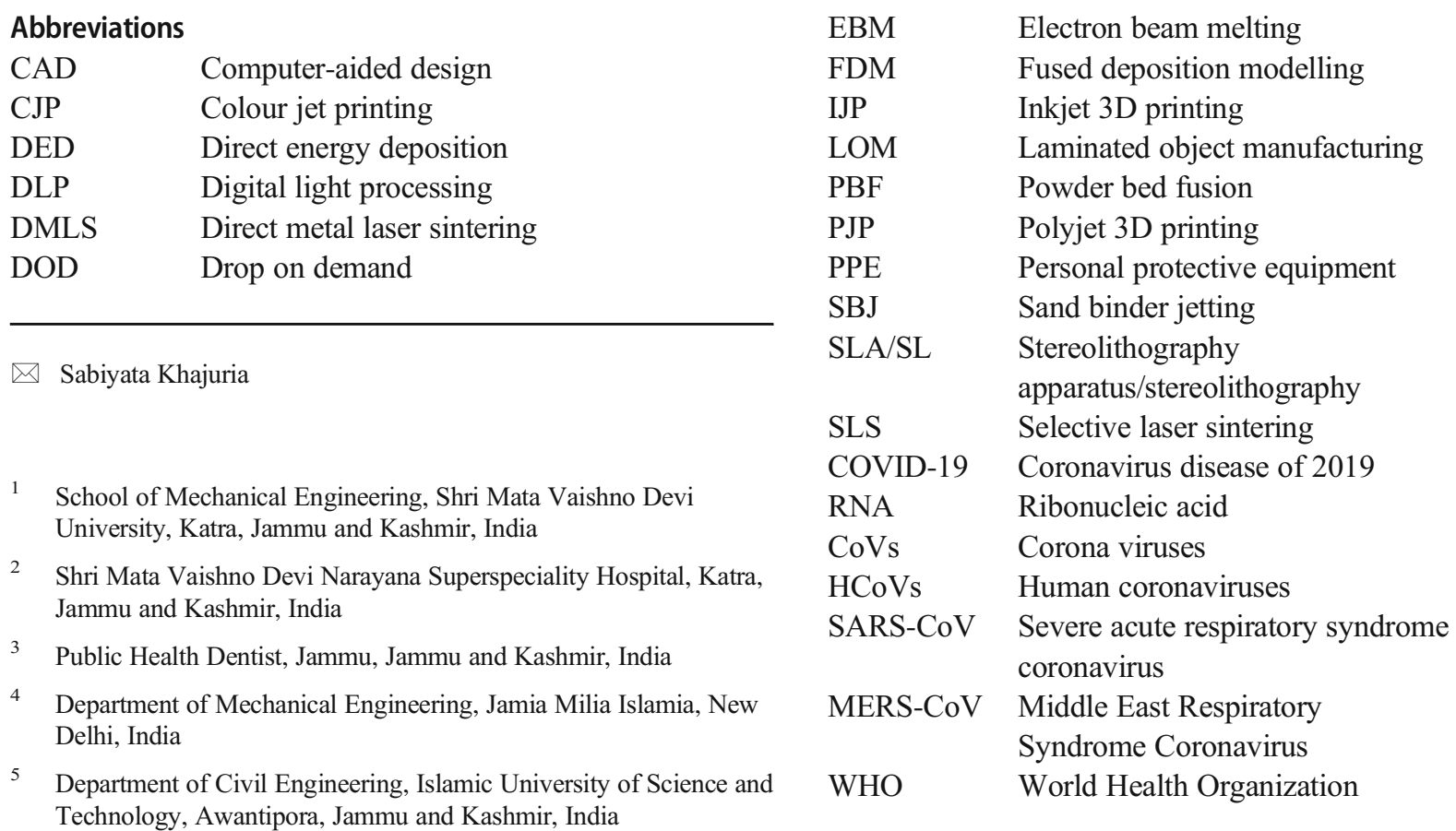




$\begin{array}{ll}\text { CDC } & \text { Centre of Disease Control and Prevention } \\ \text { DPA } & \text { Defence Protection Act } \\ \text { ICU } & \text { Intensive care unit } \\ \text { NIPPV } & \text { Non-invasive positive pressure ventilation } \\ \text { STL } & \text { Standard Tessellation Language } \\ \text { APL } & \text { Adjustable pressure limiting } \\ \text { NRL } & \text { Natural rubber latex } \\ \text { XNBR } & \text { Carboxylated nitrile butadiene rubber }\end{array}$

\section{Introduction}

3D printing is an additive manufacturing process by which products are manufactured layer by layer techniques from digital CAD files (Singh and Chhabra, 2017). This technology is preferred in the medical field due to its capability of customisation. The medical field requires customised parts because of diverse patient data. This technology can adapt to any changes as per the patient requirement (Marro et al., 2016). Different softwares are available to design medical parts rapidly, which can further be easily $3 \mathrm{D}$ printed in lesser time and cost. The $3 \mathrm{D}$ printing technology has led to a considerable shortening of the product development cycles (Conner et al., 2014). Major 3D printing technologies available in the market include stereolithography (SLA), selective laser sintering (SLS), fused deposition modelling (FDM), direct metal laser sintering (DMLS), laminated object manufacturing (LOM), colour jet printing (CJP), sand binder jetting (SBJ), inkjet 3D printing (IJP), electron beam melting (EBM), digital light processing (DLP), polyjet 3D printing (PJP) and drop on demand (DOD) (Negi et al., 2013; Lee et al., 2017). These technologies have a high capability to print complex-shaped products economically. The modification of the existing products and reverse engineering can be carried out by 3D printing without much cost and labour involvement. An option of multi-material printing is also available in some technologies to meet the customer's functional requirements.

Different types of materials are used in 3D printing to manufacture the essential medical parts (Durfee and Iaizzo, 2019). These printing technologies can manufacture lightweight, transparent, durable, flexible and biocompatible materials to fulfil the required demand. Figure 1 shows the various materials which can be printed by using 3D printing technology.

Recently, much research has been focussed towards the development of composites with 3D printing. Further, 3D printing has the ability to develop materials such as functionally graded materials, having potential medical applications in orthopaedics (Cai, 2015) and dentistry (Dawood et al., 2015) .
Further, the biocompatible materials such as titanium alloys, which are otherwise difficult to manufacture, are easy to manufacture with $3 \mathrm{D}$ printing ( $\mathrm{Ngo}$ et al., 2018). The printing of metals by $3 \mathrm{D}$ printing technique involves melting of metallic feedstock which can be either in a powder or a wire form. A solid part is obtained via layer by layer transformation of the melted part. Powder bed fusion (PBF) and direct energy deposition (DED) are the two main printing metal methods. PBF technique is used in the manufacturing of many metallic materials such as some aluminium alloys, stainless steel, nickel-based alloys, titanium and its alloys (Dutta and Froes, 2015).

For the fabrication of various polymers and composites, specific $3 \mathrm{D}$ printing techniques like stereolithography, selective laser sintering (SLS), fused deposition modelling (FDM), 3D bioprinting and inkjet printing are used. Polymer composites and thermoplastics with a low melting point are fabricated mainly by the FDM technique (Chadha et al., 2019; Aziz et al., 2020). Mechanical properties of various polymer composites can be enhanced by the addition of fibre as reinforcement. Nanomaterials are also incorporated in $3 \mathrm{D}$ printing as they are quite effective in lowering the sintering temperature and also enhancing the mechanical and electrical properties of the host matrix. Manufacturing of various advanced ceramics is also accomplished with $3 \mathrm{D}$ printing, which finds various applications in tissue engineering and the production of various biomaterials (Ho et al., 2015; Javaid and Haleem, 2018; Haleem and Javaid, 2020).

Given the discussion mentioned above, the main aim of this work is to review the advancements related to $3 \mathrm{D}$ printing to develop medical equipment and to highlight the potential of $3 \mathrm{D}$ printing in addressing the growing demand for medical equipment mainly the personal protective equipment (PPE) amidst COVID-19 pandemic or during future emergency conditions. Further, we suggest how low-cost FDM 3D printing technologies such as FDM can print customised medical parts in lesser time and cost without any tooling and fixtures.

The review is carried out by identifying and studying relevant and recent papers by searching keywords such as "3D printing and COVID-19", "3D printing and Masks", "3D printing and medical equipment" and "3D printing and ventilators", etc. from the relevant knowledge databases. Around 50 relevant papers are identified and included in the review; however, to gain an insight into the allied fields, around 120 articles were studied. Based on the relevance and context of COVID19 , recent articles, wherein the potential of $3 \mathrm{D}$ printing for the development of medical equipment critical for COVID-19 was highlighted, were included in this review. Also, articles which do not convey any substantial 


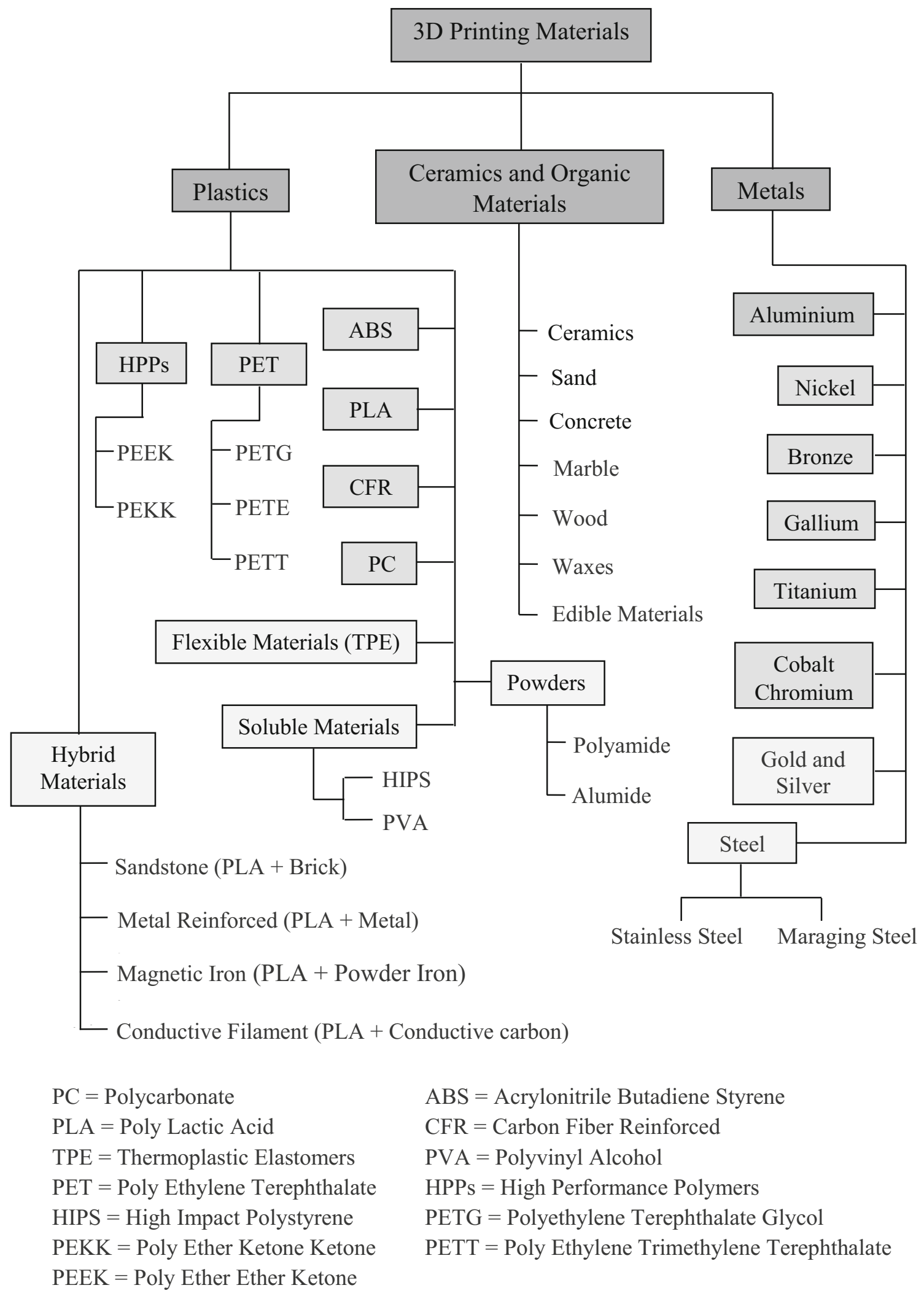

Fig. 1 Broad classification of different 3D printing materials

information concerning $3 \mathrm{D}$ printing and COVID-19 were excluded. Moreover, articles containing too much technical jargon were excluded keeping in view the wide and interdisciplinary prospective readership. 


\section{Overview of coronavirus}

Coronaviruses are a group of related viruses identified in causing diseases in mammals and birds (Ismail et al., 2003; Cavanagh, 2007). Coronaviridae are enveloped, single positive-sense stranded RNA (26-32 kb) viruses ( $\mathrm{Su}$ et al., 2016) that can be divided into four genera: alpha, beta, delta and gamma, of which alpha and beta CoVs are known to infect humans (Tripp and Tompkins, 2018). Coronaviridae pathogenic to humans or human coronaviruses $(\mathrm{HCoVs})$ is considered inconsequential pathogens, causing common cold in otherwise healthy persons. The two previous notable exceptions in the twenty-first century include the severe acute respiratory syndrome coronavirus (SARS-CoV), a novel betacoronavirus that emerged in Guandong, Southern China (Peiris et al., 2004) and the famous middle east respiratory syndrome coronavirus (MERS-CoV), first detected in Saudi Arabia in 2012 (Zaki et al., 2012) emerging from animal reservoirs leading to global epidemics with startling morbidity and mortality. In December 2019, another pathogenic HCoV,
Fig. 2 Pie chart showing a worldwide COVID-19 cases, b

deaths due to COVID-19

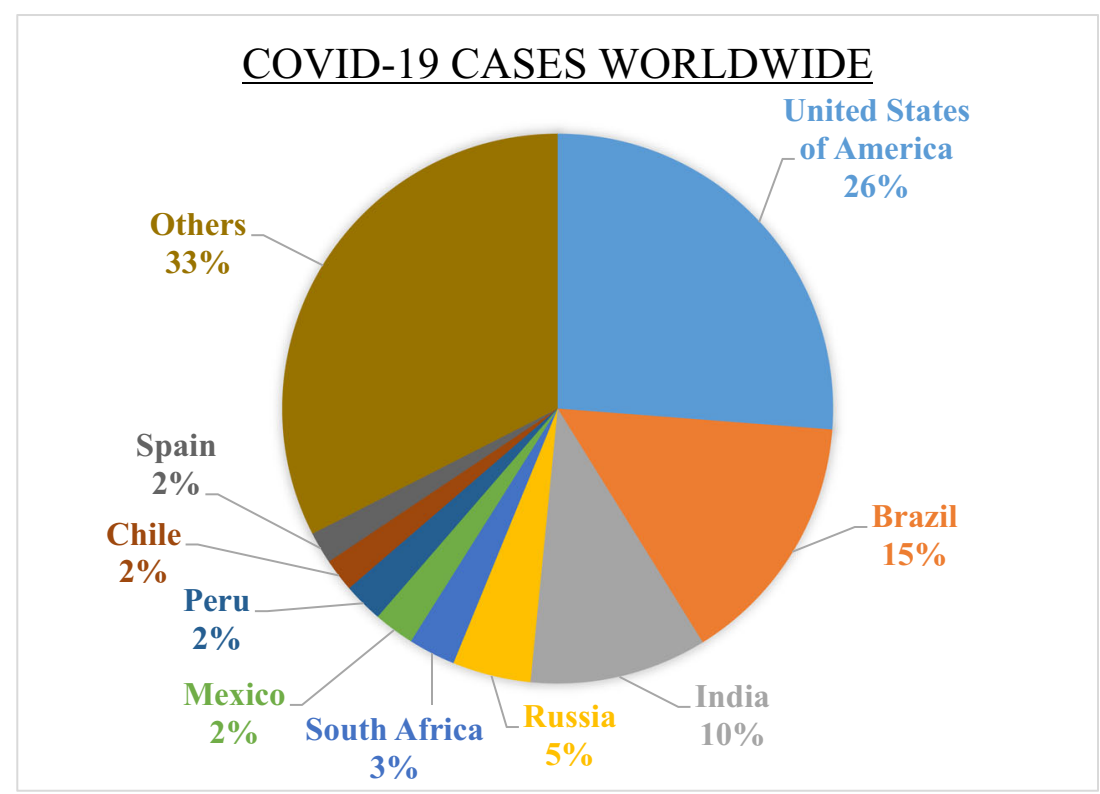

(a)

\section{WORLDWIDE DEATHS DUE TO COVID-19}

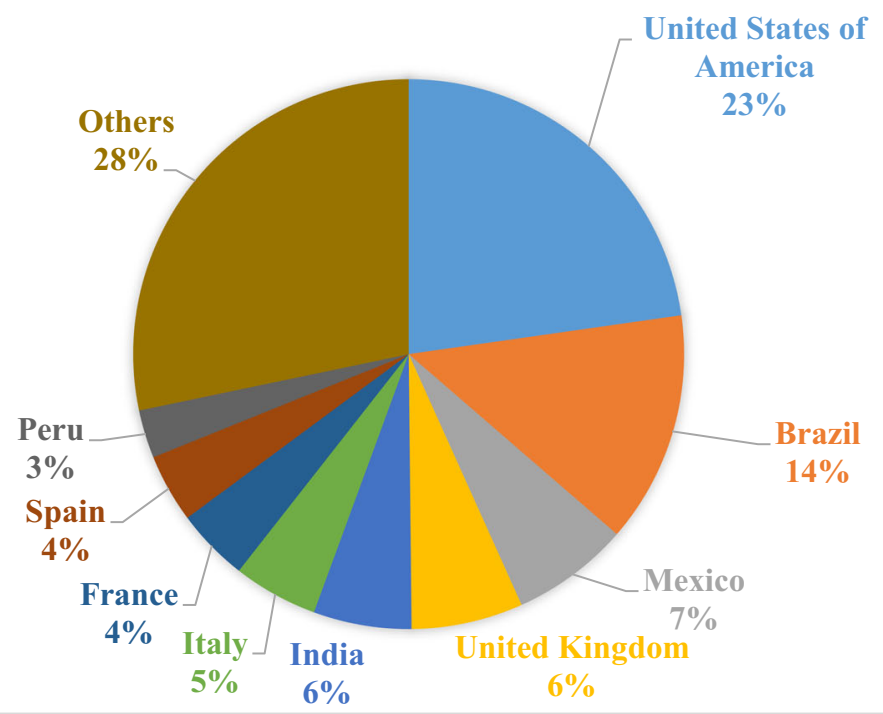

(b) 
a novel enveloped RNA beta-coronavirus, was recognised in Wuhan, the capital city of Hubei province in China (Huang et al., 2020), which has led to serious illness and death and been named as severe acute respiratory syndrome coronavirus-2 (SARS-CoV-2), phylogenetically similar to SARS-CoV (Zhu et al., 2019).

On March 11, 2020, the World Health Organization designated "Coronavirus Disease 2019" (COVID-19) as a global pandemic. As of 5th August 2020, more than 18 million cases of COVID-19 have been reported in over 200 countries and territories, resulting in approximately 700, 000 deaths. Figure 2 shows the percentage of COVID-19 cases and deaths due to COVID-19 in top nine countries of the world (Coronavirus Update (Live) Worldometer., 2020). Scientists reported that SARS-CoV-2 did not escape from a jar. Its RNA sequences very much resemble those of viruses found in bats, and epidemiologic information implicates a bat-origin virus infecting unrevealed animal species sold at live-animal markets in China. As the number of cases in the world continues to grow, global leaders are encouraging physical (or "social") distancing to slow the transmission rate. This practice aims to flatten the curve of a new infection, thereby avoiding a surge of demand on the health care system.

\section{Global implications of COVID-19}

With a world population of over 7.8 billion people, a combined effect of altered human behaviours, environmental changes, and an inadequate global public health mechanism can quickly turn obscure animal viruses into a pragmatic human crisis (Allen et al., 2020). The classic example is coronavirus pandemic causing large-scale loss of life and human suffering (Nicola et al., 2020). This pandemic has become a cause of third and most significant economic, financial and social shock of the twentyfirst century. The self-imposed or mandatory lockdown observed by various countries has led to a halt in production in affected countries hitting supply chain across the globe. Further, a steep drop in consumption and a collapse in confidence amongst investors and consumers have also been reported (Fernandes, 2020; McKibbin and Fernando, 2020).

Apart from the socio-economic problems, the only concern throughout the world is the shortage of key medical equipment such as ventilators and personal protective equipment (PPE), including respirators, gloves, face shields gowns and hand sanitisers (Preece et al., 2020). Lack of adequate PPE for frontline healthcare workers renders them vulnerable to the pandemic, thus endangering the entire health care system's functioning. In Italy itself, the lack of adequate access to PPE has led to higher infection rates amongst the health care workers (Balmer and Pollina, 2020). In this regard, Center for Disease Control and Prevention (CDC) has recommended the use of N95 respirator masks during aerosol-generating procedures.

Table 1 Comparison of benefits of medical protection equipment developed with $3 \mathrm{D}$ printing over traditional manufacturing technology (Wu et al., 2016; Attaran, 2017; Ventola, 2014)

$\begin{array}{ll}\text { Parameter 3D printing } & \begin{array}{l}\text { Traditional manufacturing } \\ \text { technology }\end{array}\end{array}$

\begin{tabular}{lll}
\hline Cost & $\begin{array}{l}\text { The complex and } \\
\text { customised medical }\end{array}$ & $\begin{array}{l}\text { Traditional manufacturing } \\
\text { technologies are popular }\end{array}$ \\
manufactured in lesser cost & due to mass production of \\
products, so customised & product manufactured by \\
& these technologies are very \\
& costly
\end{tabular}

Time - During the COVID-19 These technologies do not outbreak, there is a re- fulfil rapid requirements in quirement of medical lesser time. equipments which can be manufactured by using 3D printing in lesser time

Quality - Quality of the product can - Quality of the equipment is be improved with the input dependent on a variety of of quality raw materials and during the post-processing step.

- Easy and fast design iterations possible to improve the quality of the products.

Risk Patient-specific medical reduc- equipment are manufactured to fulfil
desired requirements which can reduce the risk during the treatment process

Speed and

- Printing speed can be increased by increase the

flexi- layer thickness and proper bility part orientation

- Flexibility during the change in shape and size of products are easily possible using $3 \mathrm{D}$ printing technology

Strength - Lightweight materials, to functionally graded weight materials for medical ratio applications are efficiently manufactured by using 3D printing technology.

Waste Material is added layer by reduc- layer; as a result, there is tion lesser wastage of raw materials parameters and a robust quality control mechanism needed for quality improvement.

- Conventional technologies are not flexible enough to produce patient-specific equipment.

- Increasing the manufacturing speed, changing shape, and size is comparatively difficult by using conventional technologies.

- Material changing options are limited in case of traditional manufacturing processes and developing components with better strength to weight ratio for medical applications is comparatively difficult.

- Materials are removed from the raw materials, so there is very high wastage of materials, which adds to the cost of the product. 
Apart from PPEs, most of the countries are facing a shortage of ventilators due to the outbreak of COVID-19 pandemic. The demand for ventilators across the globe is ten times more than the availability and is expected to grow further (Hong J, 2020). The total number of ventilators in the USA as per the data of American Hospital Association is nearly 160,000 (Rubinson et al., 2010). Out of these, nearly 98,000 can provide basic functions leaving about 62,000 ventilators with advance facilities to cope with the severe complications caused due to COVID-19. As of now, more than 4.9 million cases have been reported in the USA, which stands at number 1, amongst the worst COVID-19-affected countries (Sanger-Katz et al., 2020). It has been observed that owing to the rapid increase in the COVID-19 cases, and there are chances that the USA is going to face the shortage of ventilators. Further, it is estimated that out of the 320 million US population $20 \%$ will be infected under severe conditions due to $\mathrm{COVID}=-19$ and the number of patients requiring intensive healthcare services may account for $3,840,000$, whereas under moderate conditions the patient requiring health care services is one-fourth of this data, i.e. 960,000 (Emanuel et al., 2020). In this regard, the USA has already taken steps to increase the number of ventilators, and there are high chances that USA may enforce Defence Production Act (DPA) to make necessary equipment (M, 2020).

More than 248,803 COVID-19 cases have been reported in Italy with more than 35,000 deaths, despite the advanced healthcare facilities. To mention a few Italy has 3.2 hospital beds per 1000 people which is even more in comparison to the USA, which has 2.8 (Rosenbaum, 2020). The number of infected healthcare workers due to COVID-19 is also high in Italy. It is primarily due to the lack of PPE, which includes the respirators, gloves, face shields, gowns and sanitisers (Ranney et al., 2020). Thus, it is clear that for developed nations like the USA and Italy, it has become a challenge to combat COVID-19, due to the surge in the number of cases and lack of ventilators and PPE. For the countries that are still in the developing phase, it will be challenging to meet the exponentially increasing demand for the medical equipment.

\section{Opinions and recommendations}

As the world braces for a mounting wave of COVID-19 patients in hospitals and intensive care units (ICUs), it needs to be ensured that our medical establishments are fully equipped with key equipment required to establish care for patients and to keep our health care personnel safe.

There is a broad range of estimates of the number of ventilators we will need to care for COVID-19 patients, from several hundred thousand to as many as a million. The estimates would vary depending on the number, speed and severity of infections. Moreover, the traditionally treated patients with non-invasive positive-pressure ventilation (NIPPV) for conditions such as exacerbation of chronic obstructive pulmonary disease may need to be presumptively intubated while awaiting COVID-19 testing results. Thus, in order to fill the gap between the availability and need of the ventilators and PPE in view of the COVID-19 pandemic, the focus must be laid on the following aspects (Ranney et al., 2020) as it has been opined that mechanical ventilation is going to be a difference between the recovery and death(X, 2020).

Table 2 Comparison of costs for developing parts by 3D printing vs conventional technologies

\begin{tabular}{|c|c|}
\hline Parameter & $3 \mathrm{D}$ printing vs conventional technologies \\
\hline Material and design costs & $\begin{array}{l}\text { 'Essential material cost is the same. However, less material is consumed due to easy geometry optimisation and very } \\
\text { lesser material wastage (Berman, 2012). } \\
\text { >The design complexity in medical equipment is achieved at a very lesser additional cost by 3D printing technologies } \\
\text { (Mobbs et al., 2017). } \\
\text { >Since design iterations are easy by 3D printing design cost is much lower than conventional processes. }\end{array}$ \\
\hline Labour costs & $\begin{array}{l}\text { 3D printing carried out automatic manufacturing with CAD model input so there is very lesser involvement of human } \\
\text { labour (Gebler et al., 2014) } \\
>\text { These technologies reduce the labour cost because products are manufactured in one go. }\end{array}$ \\
\hline Machinery costs & $>$ A low-cost 3D printer like FDM capable of printing medical equipment is available in the market (Tan et al., 2016). \\
\hline Running costs/energy costs & $\begin{array}{l}\text { There are lesser maintenance and energy cost for the smooth running of these technologies particularly FDM (Petrick } \\
\text { and Simpson, 2013) } \\
>\text { The energy input to the technologies like FDM is very less and is eco-friendly(Mello et al., 2010) }\end{array}$ \\
\hline Tooling and die costs & $\begin{array}{l}>\text { No tooling cost or cost of jigs and fixtures involved in 3D printing. } \\
\text { Only 3D printer is required which can print the part in lesser cost and time (Rayna and Striukova, 2016) }\end{array}$ \\
\hline Post processing costs & >Very little or no post processing required hence very little or no such cost involved (Rengier et al., 2010). \\
\hline
\end{tabular}


Table 3 Summary of the work carried out related to design, development and technical aspects of medical masks

\begin{tabular}{lll}
\hline S. No. & Summary of the work & Reference \\
\hline 1 & Role of masks and respiratory protection during COVID-19 highlighted & Wang and Yu (2020) \\
2 & Effectiveness of N95 respirators vs. surgical masks studied & Long et al. (2020) \\
3 & Environmental aspects of convectional surgical masks & Huang and Morawska (2019) \\
4 & - Infection susceptibility on the outer surface of masks & Chughtai et al. (2019) \\
& - Problems associated with prolonged use of conventional masks such & \\
5 & as pressure on the face, breathing difficulty, discomfort, trouble communicating, and headache. & B (2020) \\
\hline
\end{tabular}

- Increase the manpower requirement for the production of PPE.

- Direct the other private companies to produce PPE and ventilators using DPA.

- Explore for alternate technologies such as 3D printing or additive manufacturing for the production of PPE.

- A collaboration of different industrial setups to increase the production of PPE.

- Restrict/minimise the use of masks and gloves in the nonmedico activities.

- Judicious use of available PPE.

- Implementation/use of effective supply chain management.

\section{Potential of 3D printing for production of medical equipment}

The various technical benefits associated with 3D printing technologies in general and fused deposition modelling (FDM) in particular makes $3 \mathrm{D}$ printing a promising solution to manufacture medical equipment for the emerging medical crisis. Table 1 summarises the benefits offered by $3 \mathrm{D}$ printing technologies in comparison with conventional manufacturing processes, whereas Table 2 gives an account of costeffectiveness of the 3D printing technologies, particularly FDM technology.

The printing is possible through remote access mode with minimal human interventions, ensuring the safety of the personnel involved in mask manufacturing. The following sections present the viability of $3 \mathrm{D}$ printing for the production of low-cost equipment faster.

\section{Medical masks}

The layered structure of the masks makes 3D printing a viable option for mass production of the masks. Moreover, the issue of loose-fitting associated with the conventional cloth-based masks can be dealt with by using polymeric materials for better fitting, which can be designed for a wide range of facial profiles. Table 3 summarises the work reported in this regard for designing and developing medical masks by $3 \mathrm{D}$ printing technologies. The materials used for the development of surgical masks such as polypropylene, polystyrene, polycarbonate, polyethylene, polylactic acid (PLA) and polyester are easily 3D printable by extrusion based additive manufacturing methods. Further, the low cost of the FDM based printers also offers tremendous opportunities for the developing economies which are currently under lockdown. The versatility of the process to produce complex shapes and minimal post-processing in minimum time can serve the current global need for masks. Figure 3 presents a proposed schematic on the process to develop 3D-printed masks via extrusion-based $3 \mathrm{D}$ printing.

\section{Protective gear and other equipment}

Given the kind of risk involved particularly to the medical staff, apart from the masks, much protective gear such as face shields and medical gloves can be printed on a mass scale by $3 \mathrm{D}$ printing technology. Figure 4 presents a representative image denoting the various protective gears needed for the medical professionals. Moreover, the types of equipment associated with the testing of COVID-19 patients such as syringes, test tubes, swabs, etc. made of polymeric parts can also be 3D printed and can suffice the hospitals' growing demands. Table 2 summarises the various

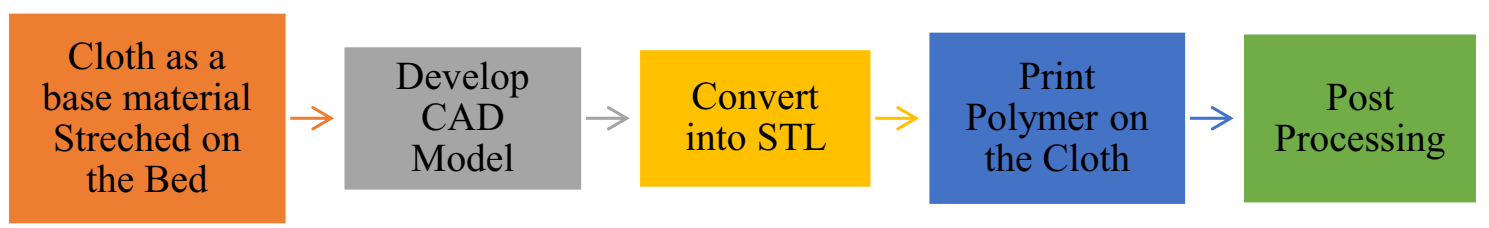

Fig. 3 Schematic for developing low-cost 3D-printed masks 


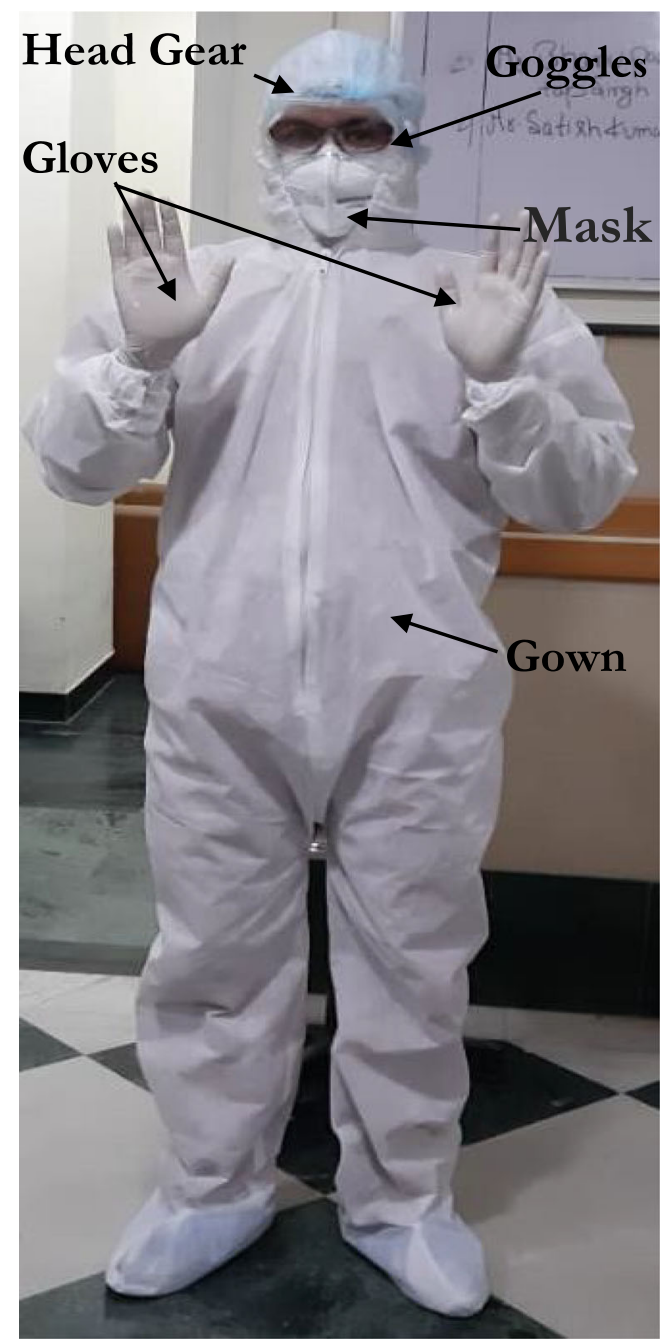

Fig. 4 Representative image of the medical protective gear

properties of the PPEs. As evident from Table 4, most of the equipment are made of polymer. Therefore, the low-cost FDM can be easily exploited for the production of these parts. Furthermore, the production of customised designs of this equipment is also possible through $3 \mathrm{D}$ printing.
Face shields are capable of protecting the face from hazards where goggles or eyewear are insufficient. 3D printing has the potential to print face shields as per the face design of the patient. Face shields also allow better hydration to the skin apart from better blood circulation in comparison with conventional masks. 3D printing has an excellent capability to print face shield rapidly. Further, 3D printing can easily print mask adjuster to meet the ongoing demand caused by COVID-19. The mask adjuster improves the comfort and adjustability of the mask.

\section{Ventilator parts}

A mechanical ventilator is a machine that aids in patient breathing (ventilate) when surgery is undergoing or is not in a position to breathe normally due to some illness. The patient is connected to the ventilator with a hollow tube (artificial airway) through the trachea's mouth. The schematic of a conventional ventilator is presented in Fig. 5. Mechanical ventilation ensures effortless breathing by the supply of adequate oxygen to the patient. Designing the ventilator for a safe, continuous and with minimum human intervention needs three basic components (Chatburn and Mireles-Cabodevilla, 2013; Huang et al., 2017):

1 The energy source to run the device

2 A unit which supplies air at the desired pressure and flows with a regulated timing and size of breaths

3 A unit to monitor the output performance of the device and the condition of the patient

While some previous researchers had opined to ramp up the ventilator stock in the hospitals for pandemic situations (Huang et al., 2017), the current shortage of ventilators particularly in the developing countries amidst the coronavirus pandemic can be solved via $3 \mathrm{D}$ printing by manufacturing the various parts of the ventilator such as values, connectors,

Table 4 Properties of the various PPEs for medical personnel

\begin{tabular}{|c|c|c|}
\hline S.No & Name of the PPE & Properties/details \\
\hline 1. & Long-sleeved gown & $\begin{array}{l}\text { - Made of polymeric material } \\
\text { - They were appropriately designed to ease the movement of the personnel. } \\
\text { - Fluid resistant } \\
\text { - Preferably disposable }\end{array}$ \\
\hline 2. & $\mathrm{P} 2 / \mathrm{N} 95$ respirator & $\begin{array}{l}\text { - Raised dome or duckbill } \\
\text { - Made of 4-5 layers } \\
\text { - Designed to provide an excellent facial fit to avoid the contamination of nose and mouth }\end{array}$ \\
\hline 3. & Face shield or goggles & - Protection of eyes from splashed blood, body fluids, excretions or secretions (including respiratory secretions) \\
\hline 4. & Gloves & $\begin{array}{l}\text { - Disposable } \\
\text { - Made commonly from natural rubber latex (NRL), nitrile (XNBR), polyvinyl chloride (PVC) and polychloroprene }\end{array}$ \\
\hline 5. & Headgear & - Made of Polymer and fluid resistant \\
\hline
\end{tabular}




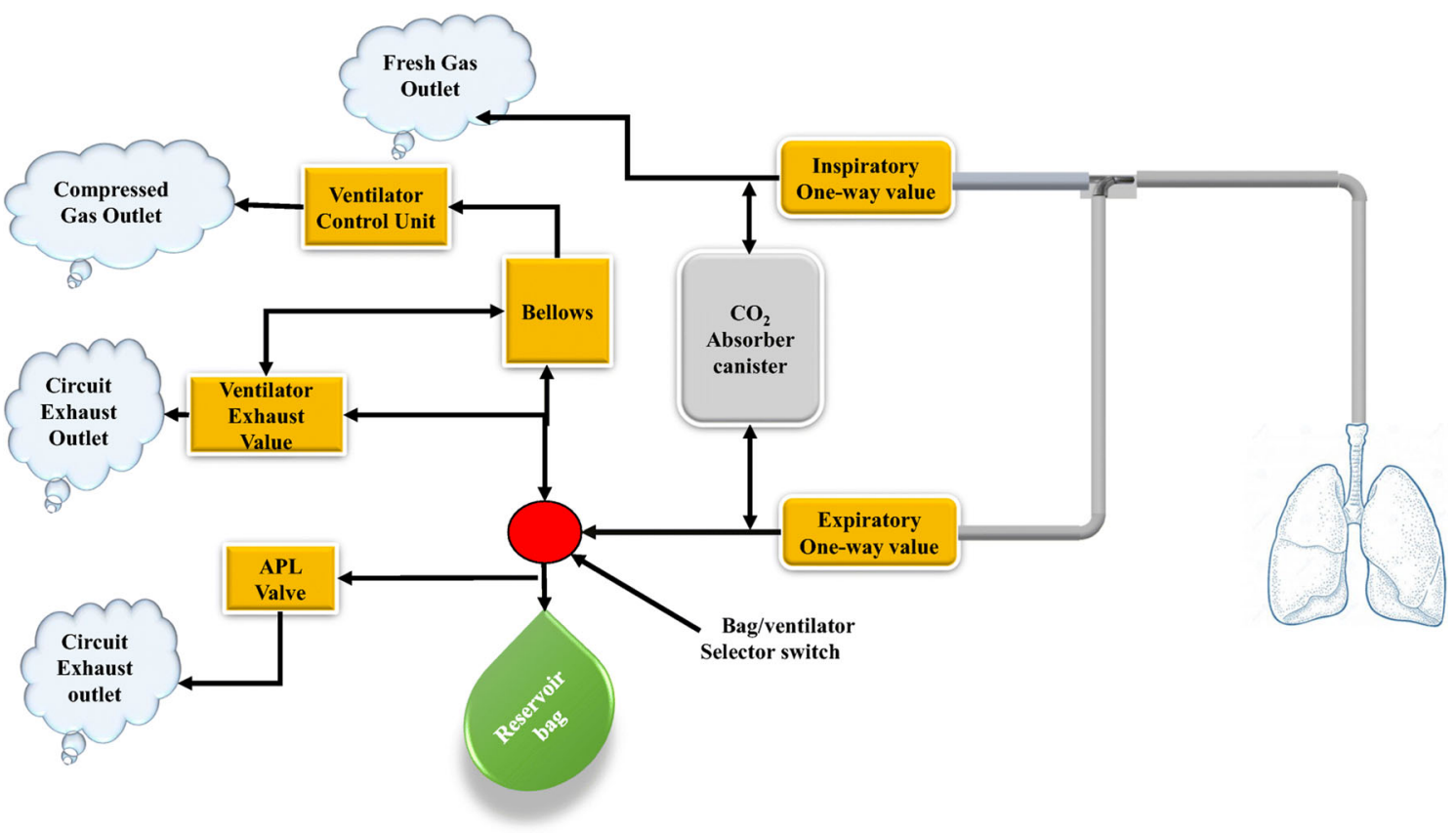

Fig. 5 Schematic diagram of a mechanical ventilator

etc. The development of low-cost locally developed ventilator may act as a lifesaving system. One good strategy is to develop low-cost connectors to divide the existing ventilator facility in order to save lives while ensuring the maintenance of proper air pressure. The ventilator parts, particularly the polymeric parts, can be manufactured in shorter time durations. Figure 6 presents an overall strategy to be followed for the printing of different types of medical equipment.

\section{Limitations and future scope}

A prerequisite for $3 \mathrm{D}$ printing is the $3 \mathrm{D} \mathrm{CAD}$ model of the product. The modelling requires extra time and cost, due to the involvement of expensive design software and skilled workforce. This poses a challenge in the current context for exploiting 3D printing potential, particularly in developing economies. Further, for a large-scale use of this technology, reverse engineering of existing products or their parts may be needed. Non-availability of the machinery, design software and skill may lead to difficulty in performing reverse engineering of parts. The current lockdown due to COVID-19 and the subsequent disruption of the supply chains, the raw material supplies are also severely affected. Therefore, the non-availability of raw materials at the consumer end is a constraint in taking full advantage of the $3 \mathrm{D}$ printing technology.

Future studies may focus on cost reduction and planning robust medical supply chains related to 3D printing. Further, dissemination of 3D printing-related knowledge and related skill development amongst the medical professionals may go a long way to deal with such future situations. More research can be undertaken in future, how low cost and rapid production can be carried out in the context of a pandemic like situations. Further, 3D printing technology needs to be augmented with the medical infrastructure to ensure better preparedness for future emergencies.

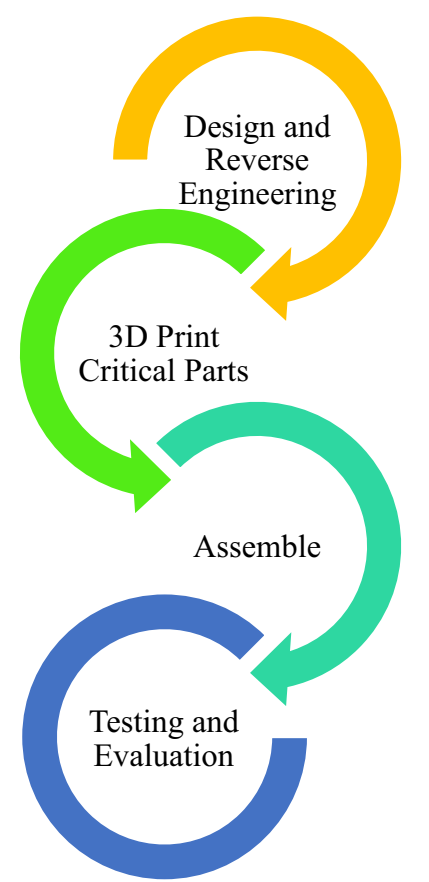

Fig. 6 Strategy for development of 3D-printed medical equipments 


\section{Conclusions and recommendations}

COVID-19 emerged rapidly amongst the whole world and has disrupted the whole supply chain of critical medical parts required for the patients and the safety equipment required for the medical professionals dealing with the situation. There is a vast gap between the demand and the supply of parts such as masks, protective gear and ventilator parts, etc. This gap can be fulfilled by a technology which could economically manufacture parts in less time. 3D printing, because of its intrinsic advantages, offers a solution to the emergent need in the medical field. This technology can be introduced to manufacture the critical items required for the safety of COVID-19. Further, 3D-printed personal protective equipment such as mask, protective gears, ventilator parts, face shield, mask adjuster and other essential equipment can emerge more efficiently in dealing with the pandemic situation, saving human lives globally. The minimum human interventions required to carry out production using $3 \mathrm{D}$ printing also makes the technology a good option to deal with the current situation. The paper systematically summarises and reviews the potential of 3D printing in fighting COVID-19. The opinions, recommendations and suggestions put forward in work shall act as a stimulant globally to exploit 3D printing potential in fighting COVID-19.

Acknowledgements The authors are thankful to in charge of Research Lab, School of Mechanical Engineering, SMVD University, Katra.

\section{Compliance with ethical standards}

This paper does not contain any study performed by any of the authors with human participants or animals.

Conflict of interest The authors declare that they have no conflict of interest.

\section{References}

Allen J, Burns N, Garrett L, Haass RN, Ikenberry GJ, Mahbubani K, et al. How the world will look after the coronavirus pandemic. Foreign Policy. 2020;20:2020.

Attaran M. The rise of 3-D printing: the advantages of additive manufacturing over traditional manufacturing. Bus Horiz. 2017:60:677-88.

Aziz R, Haq MIU, Raina A. Effect of surface texturing on friction behaviour of 3D printed polylactic acid (PLA). Polym Test. 2020;85: 106434.

Balmer C, Pollina E. Italy's Lombardy asks retired health workers to join coronavirus fight. World Econ. Forum, Reuters, 2020.

Berman B. 3-D printing: the new industrial revolution. Bus Horiz. 2012;55:155-62.

Cai H. Application of 3D printing in orthopedics: status quo and opportunities in China. Ann Transl Med. 2015;3.

Cavanagh D. Coronavirus avian infectious bronchitis virus. Vet Res. 2007;38:281-97.
Chadha A, Haq MIU, Raina A, Singh RR, Penumarti NB, Bishnoi MS. Effect of fused deposition modelling process parameters on mechanical properties of 3D printed parts. World J Eng. 2019;16:550-9.

Chatburn RL, Mireles-Cabodevilla E. Basics principles of ventilator design. Princ Pract Mech Vent 3rd Edn McGraw-Hill, New York. 2013:65-97.

Chughtai AA, Stelzer-Braid S, Rawlinson W, Pontivivo G, Wang Q, Pan $\mathrm{Y}$, et al. Contamination by respiratory viruses on outer surface of medical masks used by hospital healthcare workers. BMC Infect Dis. 2019;19:1-8.

Conner BP, Manogharan GP, Martof AN, Rodomsky LM, Rodomsky $\mathrm{CM}$, Jordan DC, et al. Making sense of 3-D printing: creating a map of additive manufacturing products and services. Addit Manuf. 2014;1:64-76.

Coronavirus Update (Live): 1, 365, 330 Cases and 76, 504 Deaths from COVID-19 virus outbreak - Worldometer. 2020. Available from: https://www.worldometers.info/coronavirus/?utm_campaign= homeAdvegas 1 ?

Dawood A, Marti BM, Sauret-Jackson V, Darwood A. 3D printing in dentistry. Br Dent J. 2015;219:521-9.

Durfee WK, Iaizzo PA. Medical applications of 3D printing. Eng. Med., Elsevier; 2019, p. 527-43.

Dutta B, Froes FHS. The additive manufacturing (AM) of titanium alloys. Titan. powder Metall., Elsevier; 2015, p. 447-68.

Emanuel EJ, Persad G, Upshur R, Thome B, Parker M, Glickman A, Zhang C, Boyle C, Smith M, Phillips JP. Fair allocation of scarce medical resources in the time of Covid-19. 2020.

Fernandes N. Economic effects of coronavirus outbreak (COVID-19) on the world economy. Available SSRN 3557504. 2020.

Gebler M, Uiterkamp AJMS, Visser C. A global sustainability perspective on 3D printing technologies. Energy Policy. 2014;74:158-67.

Haleem A, Javaid M. 3D printed medical parts with different materials using additive manufacturing. Clin Epidemiol Glob Heal. 2020;8: 215-23.

Ho CMB, Ng SH, Yoon Y-J. A review on 3D printed bioimplants. Int J Precis Eng Manuf. 2015;16:1035-46.

Hong J LD\& B. World ventilator demand is now 10 times what's available, says China's top medical device maker. 2020.

Huang W, Morawska L. Face masks could raise pollution risks. 2019

Huang H-C, Araz OM, Morton DP, Johnson GP, Damien P, Clements B, et al. Stockpiling ventilators for influenza pandemics. Emerg Infect Dis. 2017;23:914-21.

Huang C, Wang Y, Li X, Ren L, Zhao J, Hu Y, et al. Clinical features of patients infected with 2019 novel coronavirus in Wuhan, China. Lancet. 2020;395:497-506.

Ismail MM, Tang Y, Saif YM. Pathogenicity of Turkey coronavirus in turkeys and chickens. Avian Dis. 2003;47:515-22.

Javaid M, Haleem A. Additive manufacturing applications in medical cases: a literature based review. Alexandria J Med. 2018;54:411-22.

Lee J-Y, An J, Chua CK. Fundamentals and applications of 3D printing for novel materials. Appl Mater Today. 2017;7:120-33.

Long Y, Hu T, Liu L, Chen R, Guo Q, Yang L, et al. Effectiveness of N95 respirators versus surgical masks against influenza: a systematic review and meta-analysis. J Evid Based Med. 2020;13:93-101.

Marro A, Bandukwala T, Mak W. Three-dimensional printing and medical imaging: a review of the methods and applications. Curr Probl Diagn Radiol. 2016;45:2-9.

McKibbin W, Fernando R. The economic impact of COVID-19. Econ Time COVID-19. 2020;45.

Mello CHP, Martins RC, Parra BR, de Oliveira PE, Salgado EG, Seguso RT. Systematic proposal to calculate price of prototypes manufactured through rapid prototyping an FDM 3D printer in a university lab. Rapid Prototyp J. 2010;16.

Mobbs RJ, Coughlan M, Thompson R, Sutterlin CE, Phan K. The utility of $3 \mathrm{D}$ printing for surgical planning and patient-specific implant 
design for complex spinal pathologies: case report. J Neurosurg Spine. 2017;26:513-8.

Negi S, Dhiman S, Sharma RK. Basics, applications and future of additive manufacturing technologies: a review. J Manuf Technol Res. 2013;5:75.

Ngo TD, Kashani A, Imbalzano G, Nguyen KTQ, Hui D. Additive manufacturing (3D printing): a review of materials, methods, applications and challenges. Compos Part B Eng. 2018;143:172-96.

Nicola M, Alsafi Z, Sohrabi C, Kerwan A, Al-Jabir A, Iosifidis C, et al. The socio-economic implications of the coronavirus pandemic (COVID-19): a review. Int J Surg. 2020;78:185.

Peiris JSM, Guan Y, Yuen KY. Severe acute respiratory syndrome. Nat Med. 2004;10:S88-97.

Petrick IJ, Simpson TW. 3D printing disrupts manufacturing: how economies of one create new rules of competition. Res Manag. 2013;56: $12-6$.

Preece D, Lewis R, Carré MJ. A critical review of the assessment of medical gloves. Tribol Surf Interfaces. 2020:1-10.

Ranney ML, Griffeth V, Jha AK. Critical supply shortages - the need for ventilators and personal protective equipment during the Covid-19 pandemic. N Engl J Med. 2020;382:e41.

Rayna T, Striukova L. From rapid prototyping to home fabrication: how $3 \mathrm{D}$ printing is changing business model innovation. Technol Forecast Soc Change. 2016;102:214-24.

Rengier F, Mehndiratta A, Von Tengg-Kobligk H, Zechmann CM, Unterhinninghofen R, Kauczor H-U, et al. 3D printing based on imaging data: review of medical applications. Int J Comput Assist Radiol Surg. 2010;5:335-41.

Rosenbaum L. Facing Covid-19 in Italy - ethics, logistics, and therapeutics on the epidemic's front line. N Engl J Med. 2020;382:1873-5.

Rubinson L, Vaughn F, Nelson S, Giordano S, Kallstrom T, Buckley T, et al. Mechanical ventilators in US acute care hospitals. Disaster Med Public Health Prep. 2010;4:199-206.
Sanger-Katz M, Kliffs S, Parlopiano A. These places could run out of hospital beds as coronavirus spreads. New York: New York Times; 2020.

Singh R, Chhabra M. Three-dimensional printing. 2017

Su S, Wong G, Shi W, Liu J, Lai ACK, Zhou J, et al. Epidemiology, genetic recombination, and pathogenesis of coronaviruses. Trends Microbiol. 2016;24:490-502.

Tan ETW, Ling JM, Dinesh SK. The feasibility of producing patientspecific acrylic cranioplasty implants with a low-cost 3D printer. J Neurosurg. 2016;124:1531-7.

Tripp RA, Tompkins SM. Roles of host gene and non-coding RNA expression in virus infection. vol. 419. Springer; 2018.

Ventola CL. Medical applications for 3D printing: current and projected uses. Pharm Ther. 2014;39:704.

Wang $\mathrm{Q}, \mathrm{Yu} \mathrm{C}$. The role of masks and respirator protection against SARS-CoV-2. Infect Control Hosp Epidemiol. 2020;41:746-7.

Wu N, Chen Q, Liao L, Wang X. Analysis of impact of 3D printing technology on traditional manufacturing technology. Mech. Eng. Control Syst. Proc. 2015 Int. Conf. Mech. Eng. Control Syst., 2016, p. 58-60.

$\mathrm{X}$ EN. Ventilators are key to preventing coronavirus deaths - but does the world have enough of them? 2020.

Zaki AM, Van Boheemen S, Bestebroer TM, Osterhaus ADME, Fouchier RAM. Isolation of a novel coronavirus from a man with pneumonia in Saudi Arabia. N Engl J Med. 2012;367:1814-20.

Zhu N, Zhang D, Wang W, Li X, Yang B, Song J, et al. N Engl J Med. 2019:2020.

Publisher's note Springer Nature remains neutral with regard to jurisdictional claims in published maps and institutional affiliations. 